\title{
Drip fertigation study in spring maize (Zea mays L.)
}

\section{GOVIND PARASHAR, DEVENDRA SINGH AND BHANWAR LAL JAT}

See end of the Paper for authors' affiliation

Correspondence to :

\section{GOVIND PARASHAR}

Department of Agricultural, Bhagwant University, AJMER (RAJASTHAN) INDIA

Email : govindparashar.2010 @gmail.com
- ABSTRACT : Drip system can control the rate of water application to achieve application efficiency as high as $92-95 \%$. It is also excellent for soil with higher infiltration rates. In conventional way of nutrient management, the $\mathrm{P}$ and $\mathrm{K}$ are applied as basal. However, the demand for these two macro-nutrients remains high during the entire growing season. Splitting of $\mathrm{K}$ was more beneficial than applying full $\mathrm{K}$ at time of planting in soybean. Maize is one of the crop that responses well to phosphatic fertilizers in almost all the soil types. Phosphorus plays vital role in plant nutrition. The deficiency of phosphorus in soil severely limits root and shoot growth and thereby affecting the yield. The experiment consisting of 3 irrigation regimes (100\% CPE, 80\% CPE and 60\% CPE), 2 fertilizer dose (75\% RDF and 100\% RDF), 2 PK splitting (equal and 70/30) along with 2 control treatments (flood IW: CPE 0.8 with mulch and flood IW:CPE 1.0) was laid out in Split Plot Design with three replications. From findings of present investigation based on cob weight without husk it can be inferred that spring maize in sandy loam soil should be irrigated at $80 \% \mathrm{CPE}$. It should be fertilized at 90:45:30 N, $\mathrm{P}_{2} \mathrm{O}_{5}, \mathrm{~K}_{2} \mathrm{O} \mathrm{kg} / \mathrm{ha}$ with $\mathrm{PK}$ application as 70\% upto tasseling and 30\% thereafter.

- KEY WORDS : CPE, RDF, PK, LAI, NPK

- HOW TO CITE THIS PAPER : Parashar, Govind, Singh, Devendra and Jat, Bhanwar Lal (2017). Drip fertigation study in spring maize (Zea mays L.). Internat. J. Agric. Engg., 10(2) : 379-400, DOI: 10.15740/HAS/IJAE/10.2/379-400. 